\title{
Photo-Texting, a Self-Assessment Technique for the Home Food Environment
}

\author{
Lesli Biediger-Friedman*, Kristen Lines, Monica Silva \\ School of Family and Consumer Sciences Department, Texas State University, San Marcos City, USA \\ *Corresponding author: lb47@txstate.edu
}

\begin{abstract}
This paper explores a methodology of photo-texting to assess and improve upon the home food environment (HFE); a method which aims to engage participants with nutrition and food security among households. Various approaches to assessing and intervening within the HFE have demonstrated the efficacy of strengthening household food practices, improving food security, and dietary behaviors. However, public health practitioners face barriers in assessing the HFE. These include the intimate nature of the home setting, as well as the significant time, labor, and costs required to complete a comprehensive HFE assessment. Photo elicitation, though, provides a flexible strategy, while also empowering participants and conserving the resources of practitioners. This technique permits the collection of reflective self-assessments and provides a platform for goal setting. In this paper, we describe the step-by-step method of a photo elicitation technique that was developed to overcome the challenges with HFE research techniques. Furthermore, the described method may be beneficial as a practice tool to coach participants to self-assess their nutrition environment and to recognize behavioral factors within their homes and families. A pilot study of the photo-texting technique was implemented to identify lessons learned and illustrate feasibility. Results from the pilot study reveal participant engagement in all photo assignment, food and nutrition trends within the HFE, and effective goal setting techniques. Furthermore, participants reported favorable attitudes toward this technique of community-participatory research. There are many opportunities to facilitate effective HFE changes by utilizing the photo-texting technique and applying it to public health practice and research settings.
\end{abstract}

Keywords: photo voice, smartphones, home food environment, family meals, community-based participatory research

Cite This Article: Lesli Biediger-Friedman, Kristen Lines, and Monica Silva, "Photo-Texting, a Self-Assessment Technique for the Home Food Environment.” Journal of Food Security, vol. 5, no. 3 (2017): 66-74. doi: 10.12691/jfs-5-3-2.

\section{Introduction}

Historically, community participatory research methods that accommodate participant needs and preferences have been developed to facilitate community engagement [1]. One such participatory method is photo-voice, which builds awareness and empowerment among participants through documentary photography. Photo-voice captures qualitative data that transcends the limitations of language and places it in the context of a theoretical framework $[2,3]$. In recent studies, photo-voice has been instrumental in identifying environmental barriers to healthy eating and physical activity in families with young children [4,5]. With the surge of mobile device usage, though, a medium exists that can provide an inexpensive, effective mechanism for communicating with participants and collecting self-assessment data [6]. Photo-texting (photo elicitation through mobile devices) is a progression from photo-voice that yields new potential to engage people and communities, making it a promising environmental assessment method.

In photo-texting, participant-generated photos sent over mobile devices are used to elicit comments from and initiate discussions with participants. Photo-texting follows an evidence-based approach by providing an accessible and efficient assessment tool [7]. Added benefits of photo-texting include empowering participants to become assessors of their environments; reducing communication barriers, as the method does not make high literacy requirements; reducing assessment costs; and reducing training time and expenses [2,3].

The home food environment (HFE) is a relevant setting for addressing early childhood nutrition. The household's physical, social, and environmental influences play integral roles in family dietary behaviors. Assessments of the environment will reflect dietary practices and food access, which may inform environmental cues within the home $[8,9,10]$. Additionally, reflecting on insights to one's environment gained through photo-texting may provide an impetus for change $[11,12,13]$.

Self-assessment techniques represent a convenient and effective method for addressing problems with common assessment practices, which include lack of the time, money, and knowledge needed to use them properly $[13,14,15]$. Recent studies have relied on self-monitoring methods to address interpersonal dietary behavior and improve the HFE $[16,17,18]$. These methods have been used both in combination with large research team HFE 
assessments and with self-assessment as a sole indicator of the HFE. The strengths of the self-assessment components were increased self-empowerment and reduced self-stigmatization, which led to increased nutritional knowledge and perceived responsibility [11,12,14]. Through the self-awareness gained from self-assessment, barriers to an improved HFE can be identified, as can facilitators, and this can lead to potentially beneficial goal setting and an increase in healthy behaviors [11-18].

The purpose of this study is to describe a technique of photo-texting as a strategy to capture real-time self-assessments and reflect a participant's HFE. The approach considers the household demands facing families with young children and aims to promote dietary behavioral change. The aims of this article are to 1) provides a step-by-step guide to the development and implementation of a photo-texting strategy, 2) describe the HFE self-assessment observations and participant satisfaction of the HFE technique.

The description of this study will be laid out in three sections. A step-by-step method and material sections will detail the development of the photo-texting methodology. Next a results section will describe observations from the pilot implementation. Finally, a discussion and conclusions section reflects on the presented method and findings.

\section{Methods and Materials}

The following steps were devised from a pilot study developed to: 1) provide both a feasible and a targeted method to assess and improve the HFE, and to 2) provide a tool for field practitioners to address the HFE with participants and clients. The steps listed provide a detailed description of how to implement photo-texting, as well as a discussion of the strengths, limitations, and possible uses for public health professionals. Examples from the pilot project are included as lessons learned after the description of each step, to provide context to practitioners.

\subsection{Develop Photo Assignment}

First, photo assignments were created to communicate the expectations for when activities or areas of the participant's HFE should be captured with a photograph [19]. The photo assignments were between 20-25 words, and the research team assured that the photo topics were clearly explained, a submission deadline was provided, and participants consent and study information included that photos might be disseminated or shared. Additionally, participant instructions included guidance not to alter their environment prior to taking photographs (i.e., no cleaning, organization, or rearrangement of the environment).

Next, the research team identified priority assessment areas within the HFE; these are areas of the home that inform the context of each photo assignment. A literature review of modifiers to healthy behaviors within the HFE was conducted to help to identify themes to assist with the development of photo assignments. A focus was put on themes with the potential to promote critical reflection about each topic. In general, assessment areas reflecting desired project outcomes were selected; such as, household food practices are mealtime routines, the nutritional knowledge of parents, and access to foods.

Another factor to consider was the number of photo assignments needed. This number was based on the project time frame. No more than one photo assignment per day and no more than four to five per week were determined to be ideal as this number allows for daily reflection on the part of participants. The incorporation of participant "free days" were also built in to the protocol to give participants an opportunity to submit tardy assessments and enables the cohort to complete the assessments at the same rate.

\subsection{Pilot Testing}

Once photo assignments were developed, a pilot was conducted, with parents of a non-participating preschool, to identify potential problems with communications and with the planned techniques. Unforeseen data management needs were identified during pilot testing, resulting in data management technique described herin. Additionally, based on feedback from pilot groups, text message language was modified to reduce the word count, to clarify instructions, and to adjust the time frame (e.g., participants were asked to respond within 24 hours).

\subsection{Participant Recruitment and Sample}

To enroll, parents were instructed to text message the word "yes" to the research mobile phone. Researchers replied via text message with information about the photo-texting project including the start date, expectations, and how to discontinue participation at any time.

Participant demographics were obtained via a self-administered survey; a summary of the photo-texting participant demographics may be viewed in Table 1. Participants included 40 mothers and 2 fathers, between the ages of 22 and 50 years. A greater number of participants were white non-Hispanic $(n=24)$ followed by Hispanic $(n=15)$. The majority (36\%) reported earning less than $\$ 40,000$ annually per household, followed by greater than \$75,001 (33\%), and between \$40,001$\$ 75,000$ (31\%) annually.

\subsection{Study Design}

Over a three-month period, four household food areas were assessed with eight different photo assignments (two photo assignments per area). Participants were most responsive to daily text message prompts, excluding weekends (weekends were utilized as free days). Texts were sent in the morning to give participants ample time to plan for the daily assessment. During the third week, project members helped participants set goals based on their self-assessments from the first two weeks. Within each photo assignment theme, participants were encouraged to provide both facilitators and barriers. Table 2 shows categories of the photo assignments. Submission deadlines for photo assignments allowed for the progression of the assessment with a large group; however, photos were accepted up until the project's end date. Likewise, free days for participants to "catch up" with the assignment schedule provided flexibility and increased participant retention. 
Table 1. Photo-texting participant demographics $(n=42)$

\begin{tabular}{|c|c|c|}
\hline $\mathbf{M}$ & Sample (n) & $\%$ \\
\hline \multicolumn{3}{|l|}{ Household role } \\
\hline Mother & 40 & 95.24 \\
\hline Father & 2 & 4.76 \\
\hline \multicolumn{3}{|l|}{ Age (years) } \\
\hline $20-29$ & 13 & 30.95 \\
\hline 30-39 & 27 & 64.29 \\
\hline $40-49$ & 1 & 2.38 \\
\hline$>50$ & 1 & 2.38 \\
\hline \multicolumn{3}{|l|}{ Ethnicity } \\
\hline Non-Hispanic White & 24 & 57.14 \\
\hline Hispanic & 15 & 35.72 \\
\hline Black & 2 & 4.76 \\
\hline Asian & 1 & 2.38 \\
\hline \multicolumn{3}{|l|}{ Annual household income } \\
\hline$<10,000$ & 3 & 7.14 \\
\hline $10,000-20,000$ & 7 & 16.67 \\
\hline $20,001-40,000$ & 5 & 11.9 \\
\hline $40,001-75,000$ & 13 & 30.95 \\
\hline$>75,001$ & 14 & 33.33 \\
\hline \multicolumn{3}{|l|}{ Employment status } \\
\hline Unemployed & 8 & 19.05 \\
\hline Work $<40$ hrs. wk. & 8 & 19.05 \\
\hline Work $>40$ hrs. wk. & 26 & 61.9 \\
\hline \multicolumn{3}{|l|}{ Children in home (\#) } \\
\hline 1 & 19 & 45.24 \\
\hline 2 & 15 & 35.71 \\
\hline 3 & 6 & 14.29 \\
\hline $4-6$ & 2 & 4.76 \\
\hline
\end{tabular}

After a few of the scheduled photo assignments were completed, participants were asked to reflect upon the submitted self-assessments. At this point, each participant developed a short-term (e.g., over the weekend) and long-term (e.g., over the next month) goal to improve on his or her family's current dietary or other health practices. The project leaders then texted with the participant to make sure the goals were specific, measurable, attainable, realistic, and timely (SMART). Counseling with participants continued via text message or email. Nutrition education was also provided through targeted educational materials, websites, community resources, and activities for after the completion of the photo-text assessment.
Approximately 8 to 12 participants per cohort were manageable for a team of part-time staff. Each cohort began on a Monday, allowing for a full week to complete observations, and weekends to make-up for tardy submissions.

Commonly, a participant's self-assessments identified practices in need of change or explained the participant's perceptions of the HFE behind the image's relation to the topic, which sets up goal-setting opportunities. Timely responses required a project contact to check the phone regularly during daytime hours and respond to evening submissions the following morning. A verification response following each text-message submission provided assurance to the participant that his or her submission was important, and it also included helpful, supportive, and encouraging comments for effective behavior change. For example, responses acknowledged a photo submission (e.g., "thank you for your submission”), which reassured the participant that directions were properly followed (e.g., "great work!”), and/or answered participant questions. Additionally, reminder prompts encouraged participants to submit photo assignments on time.

Participants were texted a link to engage in an online survey after they completed photo-texting assignments and goal setting. The survey asked questions about the HFA assessment, goals, time requirements, and overall satisfaction. These findings were analyzed and used to evaluate the methodology.

\subsection{Data Management, Classification, and Analysis}

All photograph and text assessments were downloaded from the contact's phone data card and uploaded to a password-protected storage system or an external hard drive to ensure data safety. Next, the identified themes from the literature review were used to categorize photo assignments and create an initial code structure. Coding of text and photo submissions was done through multiple passes with an emergent theme methodology. [20] QSR International's NVivo 10, was used to organize photo and text message coding. Once all of the emergent themes were identified, further passes were used to collapse themes, or codes. The final code structure revealed the most prevalent facilitators and barriers within and across the photo-texting assignments. Figure 1 outlines the coding structure used for the photo assignments.

Table 2. Photo-texting assignment and the associated measure within the Parent Nutrition Practices model identified as a major theme within the Home Food Environment

\begin{tabular}{ll}
\hline Assessed Topic within the Home Food Environment & Photo-texting Assignment(s) \\
\hline \multirow{2}{*}{ Shaping Food Behaviors } & Your child's favorite fruit or vegetable within the home \\
& Something that gets in the way of your family eating healthy \\
Food Accessibility/Availability & View of open refrigerator \\
& View of open dry food storage area \\
Family Mealtime Routines & Tonight's family dinner preparation \\
& Tonight's family dinner \\
Goal Setting & Nutrition goal that you can achieve over the weekend \\
& Nutrition goal that you can achieve over the next month \\
\hline
\end{tabular}



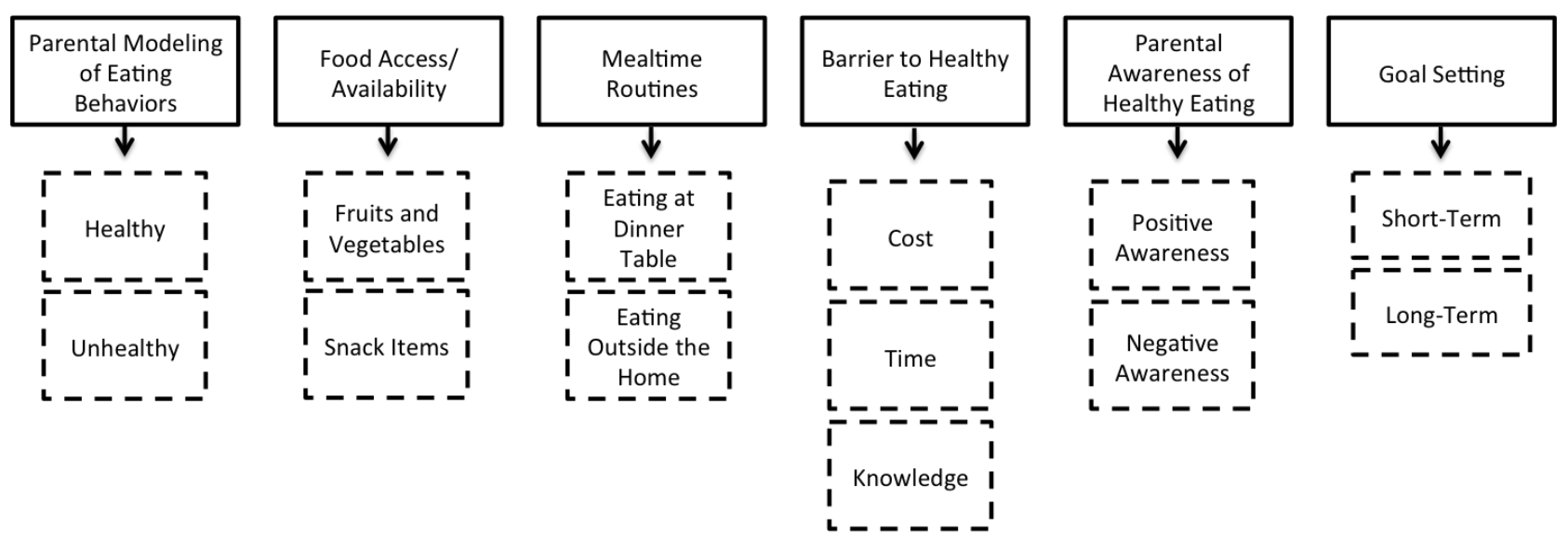

Figure 1. Coding structure developed from project model constructs and reoccurring themes from data sources. Coding structure is analyzed using QSR International NVivo 10 software

Once all photos and texts were coded by all three coders, inter-coder reliability reports were generated to assess reliability among the themes identified; inter-coder reliability gives a percentage of agreement between the three coders using the equation: \# of code agreements/\# of code decisions made. Additionally, to control for the chance of agreement among coders, kappa scores, using kappa statistic guidelines, were generated to determine the strength of coding reliability. [21] Kappa statistic guidelines are as follows: $0.75-1.00=$ excellent; 0.60-0.74 = good; $0.40-0.59$ = fair; and $<0.40$ poor. The lead coder determined whether coding disagreements were made due to error, or due to difference of opinion and/or interpretation. In the event of a coding error, the lead coder recoded the data to allow for agreement. However, in the event of a disagreement the code was left unchanged.

\section{Results}

A total of 362 photographs and 257 text reflections were submitted from the 8 photo assignments. The following major themes were identified: 1) knowledge of healthy foods and practices, 2) mealtime routines, 3) food practices, and 4 ) access and availability of foods. Table 3 provides theme reference results that represent the number of times photos and/or text reflections fit within topic themes.

\subsection{Knowledge of Healthy Foods and Practices}

The first emerging theme was parents' statements of knowledge or lack of knowledge regarding healthful foods and food behaviors. The knowledge factor most often associated with facilitating the HFE mentioned organizing and planning meals to be nutritionally balanced. One participant wrote, "we do our best to eat a balanced diet." The second most mentioned factor included statements indicating perceived benefits of healthful eating. For example, one parent stated, "we are cooking onion, it is healthy for [our] heart." Furthermore, one participant wrote "we grow our own food because it is healthier" which was reflected within knowledge barriers such as "it's more expensive to eat fruits, veggies, and meat unless you grow it yourself." Additional barrier statements included "not knowing how to correctly read food labels" and "I don't know how to grocery shop for healthy food on a budget." Slightly fewer knowledge barriers were identified than facilitators.

\subsection{Mealtime Routines}

The three most common facilitators of family mealtime were 1) cooking meals at home, 2) eating together as a family, and 3) eating meals at dinner table. One participant stated, "no matter how busy we get, my children and I have supper together every night of the week!” Common reported HFE barriers identified scheduling and time demands getting in the way of family meals. As one participant reported, "tonight is gymnastics night so we eat at Chick-fil-a first." Another participant stated, "it's always a struggle in evenings during the week to have time to come up with healthy meals unless I preplan on the weekend." Written reflections revealed that eating meals as a family was a priority for many parents, yet time demands often prevent home-cooked meals or eating at home together.

\subsection{Food Practices}

The three most common facilitators of family mealtime were 1) cooking meals at home, 2) eating together as a family, and 3) eating meals at dinner table. One participant stated, "no matter how busy we get, my children and I have supper together every night of the week!” Common reported HFE barriers identified scheduling and time demands getting in the way of family meals. As one participant reported, "tonight is gymnastics night so we eat at Chick-fil-a first.” Another participant stated, "it's always a struggle in evenings during the week to have time to come up with healthy meals unless I preplan on the weekend.” Written reflections revealed that eating meals as a family was a priority for many parents, yet time demands often prevent home-cooked meals or eating at home together.

\subsection{Access/Availability of Foods}

Within the major theme of food accessibility, healthier food items compared to unhealthy food items were found in the refrigerator. However, unhealthy food items exceeded healthy food items within dry food storage. In 
general, healthy foods were found about equally with unhealthy foods (Table 3). Many participants described encouraging access to healthy foods in the home, "my kiddos favorite veggie is broccoli, he has loved [broccoli] since he was an infant \& we always keep it in the house." Participants also acknowledged unhealthy food items. For example, one participant wrote: "not really sure which items I need to have in my pantry, but essentials are cereal and bread!" Reflecting on a photo of their pantry, another participant reflected with, "Ugh, lots of junk!”.
Overall, data analysis revealed that participants reported fewer barriers to a healthy HFE compared to researcher-observed barriers. Reported barriers included access to unhealthful foods, cost of healthful foods, and family time demands. One participant reflected "being on the go makes it easy to grab unhealthy snacks or fast food." Barriers observed by the researchers consisted of lack of meal planning, limited availability of healthful foods in the home, and knowledge deficits. Figure 2 include photo examples of the home food assessment texts.

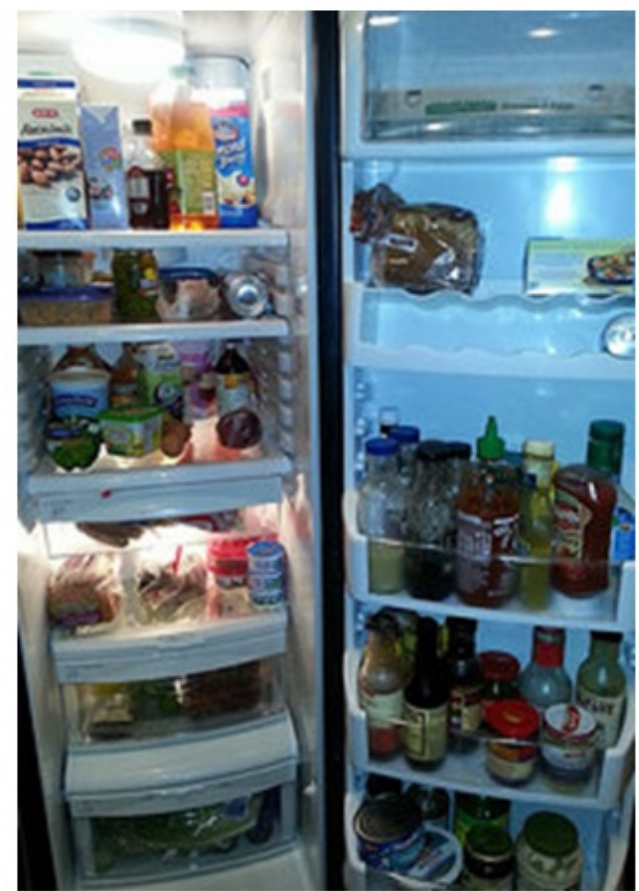

"We eat a lot of fresh fruits and veggies, some dairy, and lunch meats...My kiddo won't eat meat unless its salami or turkey sticks, and I'm not fond of cooking."

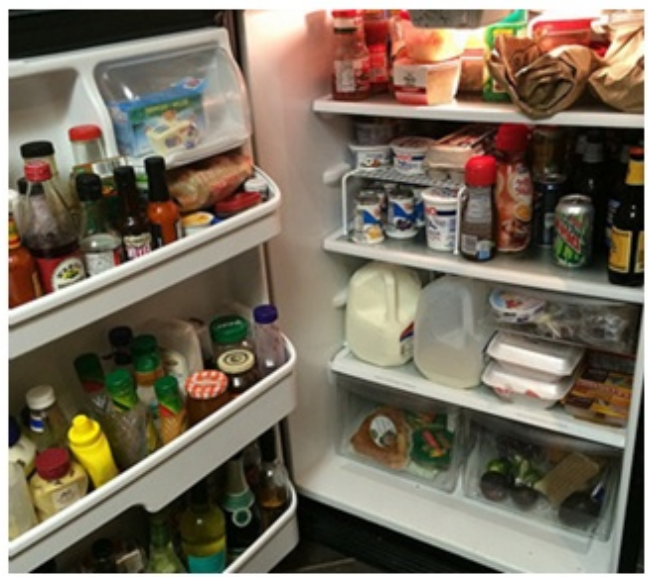

"Ugh, lots of junk!"
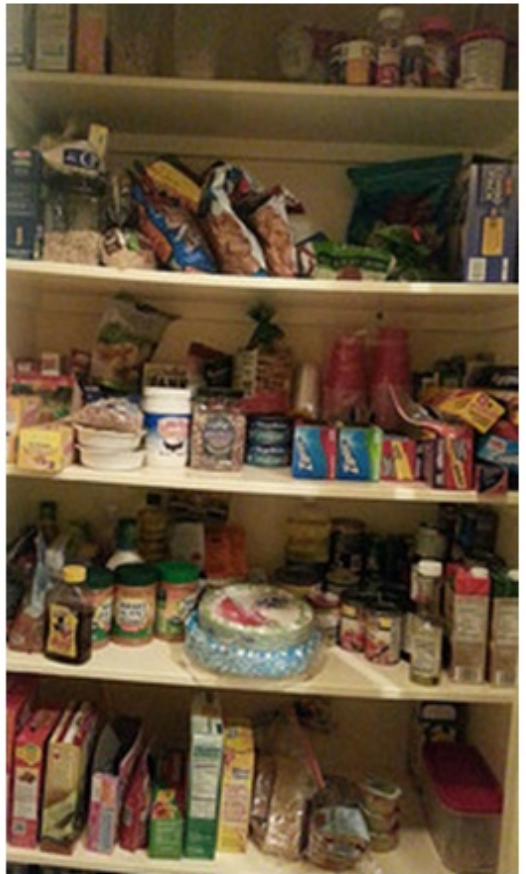

"Candies and fruit gummies are located on the top shelf and out of sight and reach."

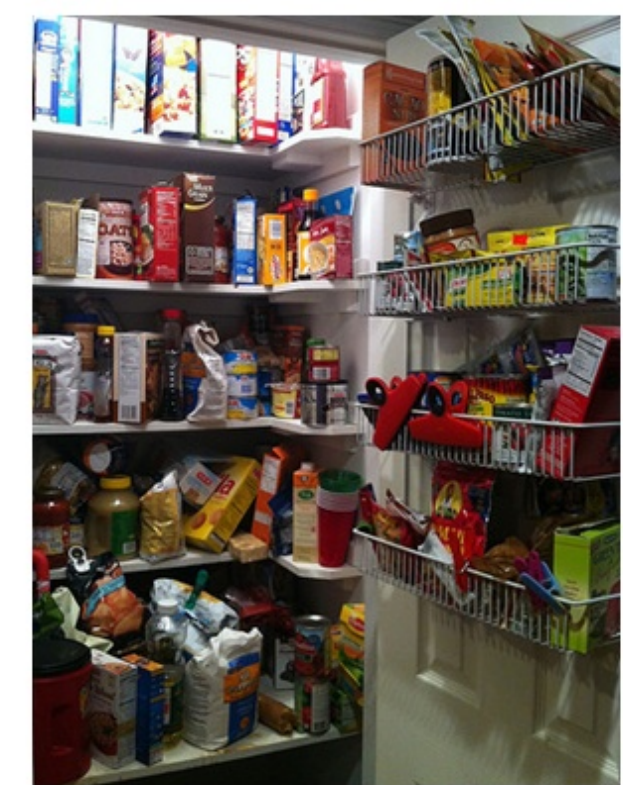

"Never really sure which items I need to have in my pantry, but essentials are cereal and bread!"

Figure 2. Pictorial and text example of the Home Food Environment submissions 
Table 3. Results of the photo-texting project categorized by facilitators and barriers within major and minor themes

\begin{tabular}{|c|c|c|c|}
\hline $\begin{array}{l}\text { Major Theme } \\
\text { Leading minor themes }\end{array}$ & Coding references & Facilitator $(+)$ & Barrier (-) \\
\hline \multicolumn{4}{|l|}{ Knowledge of Healthful Food Practices } \\
\hline Stay organized/meal plan & 12 & + & \\
\hline Benefits of healthful foods & 9 & + & \\
\hline Lack cooking skills/creativity & 8 & & - \\
\hline Unorganized/no meal planning & 8 & & - \\
\hline How to purchase healthful foods on a budget & 6 & & - \\
\hline Potential harms of unhealthy foods & 5 & + & \\
\hline Desert choices/preferences & 4 & & - \\
\hline Benefits of a home garden & 4 & + & \\
\hline Reading nutrition fact label & 2 & & - \\
\hline Portion sizes/food ingredients & 1 & & - \\
\hline Total references: & 59 & 30 & 29 \\
\hline \multicolumn{4}{|l|}{ Mealtime Routines } \\
\hline Cook food at home & 59 & + & \\
\hline Eat with family & 36 & + & \\
\hline Eat at dining table & 28 & + & \\
\hline Technology at mealtime & 8 & & - \\
\hline Family eats at separate times & 6 & & - \\
\hline Eat outside of the home & 6 & & - \\
\hline Total references: & 143 & 123 & 20 \\
\hline \multicolumn{4}{|l|}{ Food Practices } \\
\hline Serve fresh fruits/vegetables to child & 56 & + & \\
\hline Encourage healthful foods & 42 & + & \\
\hline Plan meals/shopping list & 18 & + & \\
\hline Encourage unhealthy foods & 13 & & - \\
\hline Include child in meal preparation & 11 & + & \\
\hline Unhealthy food in home/family food preferences & 10 & & - \\
\hline Consume fast foods regularly & 7 & & - \\
\hline Healthful foods at child's eye level & 4 & + & \\
\hline Home garden/chickens & 4 & + & \\
\hline No technology at mealtimes & 3 & + & \\
\hline Pack meals for school and work & 2 & + & \\
\hline Total references: & 170 & 140 & 30 \\
\hline \multicolumn{4}{|l|}{ Food Availability/Access } \\
\hline Healthful foods & 191 & + & \\
\hline Unhealthful foods & 185 & & - \\
\hline Total references: & 376 & 191 & 185 \\
\hline
\end{tabular}

Table 4. Participant evaluation survey responses by question. Exit survey responses, $n=28$ (66\%)

\begin{tabular}{|c|c|c|c|}
\hline Question & Response options & Responses & Provided commentary \\
\hline \multirow{3}{*}{$\begin{array}{l}\text { How much effort did you put into } \\
\text { taking and sending photos to us? }\end{array}$} & Very little effort & $5(17.86 \%)$ & \multirow{3}{*}{-} \\
\hline & Moderate effort & $16(57.14 \%)$ & \\
\hline & A lot of effort & 7 (25.0\%) & \\
\hline \multirow{3}{*}{$\begin{array}{l}\text { How much time per day did you spend } \\
\text { taking and sending photos to us? }\end{array}$} & $<5$ minutes & $12(42.8 \%)$ & \multirow[b]{3}{*}{ - } \\
\hline & 5-10 minutes & $12(42.8 \%)$ & \\
\hline & 10-15 minutes & $4(14.2 \%)$ & \\
\hline \multirow{2}{*}{$\begin{array}{l}\text { Did sharing your photos increase your } \\
\text { awareness of your home environment? }\end{array}$} & Yes & $23(82.14 \%)$ & \multirow{2}{*}{$\begin{array}{l}\text { "It helped me reflect on my home environment"; "it didn't } \\
\text { bother me what we were eating until I had to send photos } \\
\text { so others could see..." }\end{array}$} \\
\hline & No & 5 (17.86\%) & \\
\hline \multirow{2}{*}{$\begin{array}{l}\text { Did you change anything in your home } \\
\text { prior to taking photographs? }\end{array}$} & Yes & $3(10.71 \%)$ & \multirow{2}{*}{$\begin{array}{l}\text { "I moved some items so the picture could show more of } \\
\text { what my fridge \& pantry had since my kitchen is so } \\
\text { small." } \\
\text { "I wanted the photos to be as accurate as possible in order } \\
\text { to get the best/accurate feedback." }\end{array}$} \\
\hline & No & 25 (89.29\%) & \\
\hline \multirow{2}{*}{$\begin{array}{l}\text { Was text messaging a convenient way } \\
\text { to communicate with us? }\end{array}$} & Yes & $28(100 \%)$ & \multirow{2}{*}{$\begin{array}{c}\text { "if I was busy, I could respond when convenient"; "It } \\
\text { made what could have been an intrusive research study } \\
\text { seem accessible and manageable." }\end{array}$} \\
\hline & No & 0 & \\
\hline
\end{tabular}




\subsection{Goal Setting}

The majority of participant's goals lacked specificity; 47 of 68 submitted goals were not specific or measureable. For example, one participant responded, "our goal is to make healthy treat choices instead of bad ones over the next week." The research team formatted twenty-seven of the thirty-five short-term goals, and twenty of the thirty-three long-term goals to be specific and measureable. Leading goal categories were to consume more healthful foods such as fruit, vegetables and whole grains, followed by adopting a new nutrition practice, such as meal planning, cooking new recipes, and drinking more water. Often, participants set a goal that corresponded with identified barriers in previous photo assignments. The most commonly identified goals were reflected within the themes of knowledge and food practice barriers, such as, "my nutrition goal is to plan my family's meals for this week" and "we plan to eat these [photographed fruits, vegetables and almonds] in place of usual unhealthy treats this weekend.”

\subsection{Response Rates and Exit Survey}

Twenty-eight (66\%) participants submitted a fivequestion exit survey. In addition to multiple-choice responses, participants were provided with space to write commentary on each response. The first question asked if text messaging was convenient to communicate with researchers. All survey participants responded “yes," concluding that texting was a convenient method for this project. Provided commentary from this question included "It made what could have been an intrusive research study seem accessible and manageable" and "It didn't take much time, but it did focus attention on the topic." One participant reported that she "looked forward to the questions each day." Other responses stated that texting was great for being busy and for working around schedules with small children. The second question asked participants if they felt this project increased their awareness of their HFE. Twenty-three (82\%) respondents responded "yes" and wrote, "it helped me reflect on my home environment (areas to improve, how much time I spend on preparation of meals, etc.)" as well as "it allowed me to view what unhealthy items I have in my pantry and refrigerator." No commentary was received from participants who answered "no" to this question. The third question asked if they had arranged anything within their home prior to taking photographs; 89\% responded "no." Participant who responded "yes" to this question explained their responses: "I moved some items so the picture could show more of what my fridge \& pantry had since my kitchen is so small" as well as "I straightened the pantry a little, everything else was right from the heart.” In response to the fourth and fifth questions, perceived effort and time put into the photo-texting project respectively, the majority reported a moderate to high effort ( $57 \%$ and $25 \%$, respectively) into completing the assignments each day. Further, in response to perceived time-commitment per day, most exit survey respondents reported that photo-texting took less than 15 minutes of their time each day. No commentary was received from the effort and time perception responses. Table 4 provides a view of the exit survey results.

\subsection{Participant Feedback}

The final evaluation survey indicated generally positive feedback regarding the assessment. Survey findings yielded positive feedback regarding the methods. Participants felt the photo-texting project was convenient and worthwhile, and a majority of participants who responded to the survey indicated interest in participating in future photo-texting projects.

\section{Discussion and Implications}

Employment of photo-texting as a self-assessment method can enable community professionals to effectively connect with community members, collect extensive descriptive data regarding the HFE, and provide household-level counseling [22,23]. Participant-driven data collection enables facilitation of participants to exercise autonomy, critical thinking, and self-assessment, which are theorized to increase participation $[19,24]$. The present study, achieved a high participation rate throughout all photo assignments, which is also consistent with a recent photo voice study which found youth are active in behavior change when they engage in self or community assessment [24]. Enhanced by the perception of a small time commitment, parent participants reported willingness for photo-texting, indicating feasibility and practicality as a method for HFE self-assessment and family nutrition counseling. Furthermore, these findings are consistent with recent intervention outcomes reporting parents are highly engaged in texting methods for child obesity treatment programs [25].

Photo-texts frequently reported barriers to a healthy HFE (i.e. knowledge deficits, lack of meal planning, mealtime disruptions, family food preferences), which were consistent with those cited in previous literature among a population of parents with preschoolers [15]. Participants cited prior nutrition knowledge or deficits in knowledge as influencers of their ability to improve the HFE. The influence of knowledge on self-efficacy to overcome nutrition barriers has been demonstrated in previous studies among parents of young children [26]. This phototexting method was positive among participants and supported HFE change, potentially secondary to the individualized text messages and feedback to participants.

Goal setting with parents was a strategy facilitated by individualized text feedback; demonstrated to be a necessary step of guided self-assessment when working with parents of preschool children [27]. In the present study, the majority of goals set by participants were not specific or measurable and required coaching to revision, by a nutrition counselor on the research team. The goal refining process is time consuming for the professional, but necessary. Recent technology-based interventions found it effective to focus on setting SMART goals for dietary behavior changes [28]. Although behavior change was not followed beyond goal setting in this study, participants often set a goal that corresponded with identified 
barriers in previous photo assignments. This finding suggests that parents became more self-aware of their HFE, and were interested in the behavior change strategies.

Photo-texting allowed for goal setting, and promoted self-awareness among participants, a strength of applying this type of method to improve knowledge. The power of self-assessment is found within the participant reflection on consequences of current behaviors and photo reflection facilitates a vivid reflection. The participant can then identify common behavioral and environmental barriers to change and prioritize [30,31,32]. Additionally, self-assessments through the medium of photographs give researchers the ability to expand data collection to cover a wide scope of the HFE. It is possible, for example, to measure food access, knowledge deficits, and mealtime routines. Other strengths of photo-texting are testaments to the facile nature of this methodology. In the present study, participants described this technique as "convenient" and as "effective" due to the way it increased their awareness of current practices in the home. Moreover, this method reduces labor, as well as participant fatigue, a challenge often associated with the collection of voluminous descriptive data. Weaknesses of this study include the need for participants to have reliable and consistent access to a mobile phone. This may eliminate persons with technology knowledge deficits and/or lack of resources. Additionally, as was seen with photo-voice, photo-texting breaches participant anonymity [3,33]. Therefore, thorough photo release guidance and consent is appropriate for participants.

Applying this technique to various topics could be invaluable to public health professionals, including those working in programs such as Supplemental Nutrition for Women, Infants and Children (WIC), Supplemental Assistance Nutrition Program Education (SNAP Ed), and the Expanded Food and Nutrition Education Program (EFNEP), as a method for outpatient and family home interventions. Photo-texting can lend methodology to future studies aimed at self-assessment and behavior change. Adaptations to this technique could include family, individual, or community group self-assessment, combined with other health and dietary assessment methods (e.g., 24-hour recalls, food diaries or food frequency questionnaires), and/or included as a descriptive component of a mixed method research project.

\section{Acknowledgments}

This research was funded by a Research Enhancement Program grant from Texas State University.

\section{References}

[1] Hergenrather, K.C., Geishecker, S., McGuire-Kuletz, M., Gitlin, D.J. and Rhodes, S.D, "An introduction to community-based participatory research”, Rehab Education, 24 (3-4), 225-38, July 2010.

[2] Wang, C. and Burris, M.A, "Photovoice: Concept, methodology, and use for participatory needs assessment”, Health Education and Behavior, 24 (3), 369-87, June 1997.

[3] Harley, A, "Picturing reality: Power, ethics, and politics in using photovoice”, International Journal of Qualitative Methods, 11 (4), 320-339, September 2012.
[4] Torres, M.E., Meetze, E.G. and Smithwick-Leone, J, "Latina voices in childhood obesity: A pilot study using Photovoice in South Carolina”, American Journal of Preventive Medicine, 44 (3), S225-231, March 2013.

[5] Watts, A.W., Lovato, C.Y., Barr, S.I., Hanning, R.M. and Mâsse, L.C, "A qualitative study exploring how school and community environments shape the food choices of adolescents with overweight/obesity”, Appetite, 95, 360-367, December 2015.

[6] Pew Research Center. U.S. smartphone use in 2015. Avalable at: http://www.pewinternet.org/2015/04/01/chapter-one-a-portrait-ofsmartphone-ownership/.

[7] Jacobs, J.A., Jones, E., Gabella, B.A., Spring, B. and Brownson, C "Tools for implementing an evidence-based approach in public health practice the need for evidence-based public health", Preventing Chronic Disease, 9 (1), 1-9, 2012.

[8] Story, M., Kaphingst, K.M., Robinson-O'Brien, R. and Glanz, K, "Creating healthy food and eating environments: Policy and environmental approaches”, Annual Reviews of Public Health, 29, 253-272, April 2008.

[9] Pinard, C.A., Yaroch, A.L., Hart, M.H., Serrano, E.L., McFerren, M.M. and Estabrooks, P.A, "Measures of the home environment related to childhood obesity: A systematic review", Public Health Nutrition, 15 (01), 97-109, January 2012.

[10] Wyse, R., Campbell, E., Nathan N. and Wolfenden, L, "Associations between characteristics of the home food environment and fruit and vegetable intake in preschool children: A cross-sectional study”, BMC Public Health, 11 (1), December 2011.

[11] Baig, A.A., Benitez, A., Locklin, C.A., Gao, Y., Lee, S.M., Quinn, M.T. et al., "Picture good health: A church-based selfmanagement intervention among Latino adults with diabetes", Journal of General Internal Medicine, 30 (10), 1481-90, October 2015.

[12] Russinova, Z., Rogers, E.S., Gagne, C., Bloch, P., Drake, K.M. and Mueser, K.T, "A randomized controlled trial of a peer-run antistigma Photovoice intervention”, Psychiatric Services, 65 (2), 242-246, February 2014.

[13] Keysor, J., Jette, A. and Haley, S, "Development of the home and community environment (HACE) instrument”, Journal of Rehabilitation Medicine, 37 (1), 37-44, January 2005.

[14] Hendrie, G., Sohonpal, G., Lange, K. and Golley, R, "Change in the family food environment is associated with positive dietary change in children”, International Journal of Behavioral Nutrition and Physical Activity, 10 (1), 1, January 2013.

[15] Martin-Biggers, J., Spaccarotella, K., Hongu, N., Alleman, G., Worobey, J. and Byrd-Bredbenner, C, "Translating it into real life: A qualitative study of the cognitions, barriers and supports for key obesogenic behaviors of parents of preschoolers”, BMC Public Health, 15 (1), 189, February 2015.

[16] Golley, R.K., Hendrie, G., Slater, A. and Corsini, N, "Interventions that involve parents to improve children's weight-related nutrition intake and activity patterns - what nutrition and activity targets and behaviour change techniques are associated with intervention effectiveness?”, Obesity Reviews, 12 (2), 114-130, February 2011.

[17] Wyse, R., Wolfenden, L. and Bisquera, A, "Characteristics of the home food environment that mediate immediate and sustained increases in child fruit and vegetable consumption: Mediation analysis from the Healthy Habits cluster randomized controlled trial”, International Journal of Behavioral Nutrition Physical Activity, 12 (1), September 2015.

[18] Rosenkranz, R.R. and Dzewaltowski, D.A, "Model of the home food environment pertaining to childhood obesity", Nutrition Reviews, 66 (3), 123-40, March 2008.

[19] Woolford, S.J., Khan, S., Barr, K.L.C., Clark, S.J., Strecher, V.J. and Resnicow, K, "A picture may be worth a thousand texts: Obese adolescents' perspectives on a modified photovoice activity to aid weight loss”, Childhood Obesity, 8 (3), 230-6, June 2012.

[20] Corbin, J. and Strauss, A, Basics of Qualitative Research, Theoretical Sampling. Sage Publications, Los Angeles, 2008, 151194.

[21] de Vet, H.C., Terwee, C.B., Knol, D.L. and Bouter, L.M, "When to use agreement versus reliability measures", Journal of Clinical Epidemiology, 59 (10), 1033-1039, October 2006.

[22] Robinson, E., Higgs, S., Daley, A. J., Jolly, K., Lycett, D., Lewis, A. and Aveyard, P, "Development and feasibility testing of a smart phone based attentive eating intervention”, BMC Public Health, 13 (1), 639, July 2013. 
[23] Findholt, N.E., Michael, Y.L. and Davis, M.M, "Photovoice engages rural youth in childhood obesity prevention”, Public Health Nursing, 28 (2), 186-192, March 2012.

[24] Thomas, H.C., Irwin, J.D, "Using photovoice with at-risk youth: In a community-based cooking program," Canadian Journal of Dietetic Practice and Research, 74(1), 14-20, February 2013.

[25] Sharifi, M., Dryden, E.M., Horan, C.M., Price, S., Marshall, R., Hacker, K., Finkelstein, J.A. and Taveras, E.M, "Leveraging text messaging and mobile technology to support pediatric obesityrelated behavior change: A qualitative study using parent focus groups and interviews", Journal of Medical Internet Research, 15(12), 272, December 2013.

[26] Arsenault, L.N., Xu, K., Taveras, E.M. and Hacker, K.A, "Parents' obesity-related behavior and confidence to support behavioral change in their obese child: Data from the STAR study", Academic Pediatrics, 14 (5), 456-462, October 2014.

[27] Birch, L.L. and Fisher, J.O, "Mothers' child-feeding practices influence daughters' eating and weight", The American Journal of Clinical Nutrition, 71 (5), 1054-1061, May 2000.

[28] O'donnell, S., Greene, G.W. and Blissmer, B, "The effect of goal setting on fruit and vegetable consumption and physical activity level in a web-based intervention", Journal of Nutrition Education and Behavior, 46 (6), 570-575, December 2014.

[29] Gilliland, J., Sadler, R., Clark, A., O’Connor, C., Milczarek, M. and Doherty, S, "Using a smartphone application to promote healthy dietary behaviours and local food consumption”, BioMed Research International, 2015, August 2015.

[30] Carlson, E.D, "Photovoice as a social process of critical consciousness", Qualitative Health Research, 16 (6), 836-852, July 2006.

[31] Østbye, T., Mann, C.M., Vaughn, A.E., Brouwer, R.J.N., Neelon, S.E.B., Hales, D., Bangdiwala, S.I., Ward, D.S, "The keys to healthy family child care homes intervention: Study design and rationale," Contemporary Clinical Trials, 40: 81-89, January 2015.

[32] Glanz, K. and Rimer, B.K, Cognitive-Behavioral Models: Leading the way in individual and interpersonal theories. In: Theory at a Glance: A Guide for Health Promotion Practice. U.S Department of Health and Human Services, Washington D.C., 1997, 16-30.

[33] Riley, R.G. and Manias, E, "The uses of photography in clinical nursing practice and research: A literature review", Journal of Advanced Nursing, 48 (4), 397-405, November 2004. 